\title{
Marka Nefretinin Nedenleri ve Sonuçları Üzerine Görgül Bir Çalışma ${ }^{1}$
}

\author{
Betül BALIKÇIOĞLU \\ Sorumlu Yazar, Hatay Mustafa Kemal Üniversitesi, İktisadi ve İdari Bilimler Fakültesi, \\ İsletme Bölümü \\ bbalikci@gmail.com,ORCID:0000-0001-7043-2544
}

\author{
Fatih Mehmet KIYAK \\ Hatay Mustafa Kemal Üniversitesi, Antakya Meslek Yüksek Okulu, \\ fmkiyak@outlook.com,ORCID: 0000-0002-4209-9526
}

\begin{abstract}
$\ddot{O} \mathbf{z}$
Tüketim karşıtlığı alan yazınında tüketicilerin markalarla olan ilişkisi, pozitif ve negatif duygularla ilişkilendirilmektedir. Marka nefreti, tüketicinin markalara yönelik olumsuz duygularından birisi olarak belirli bir markadan hoşlanmamaktan ziyade daha yoğun olumsuz bir duygu durumudur. Çalışmanın amacı, sembolik uyuşmazlık ve ideolojik uyumsuzluğun marka nefreti üzerindeki etkisi ile marka nefreti sonuçlarının belirlenmesidir. Tüketicilerin marka nefreti, yüksek teknoloji ürünü olan akıllı cep telefonlarıyla sınırlandırılmıştır. Araştırmanın verileri, 215 tüketiciden anket yöntemi ile toplanmıştır. Araştırma hipotezleri, yapısal eşitlik modeli ile test edilmiştir. Analiz sonuçlarına göre hem sembolik uyuşmazlık hem de ideolojik uyumsuzluk marka nefretini pozitif yönde ve anlamlı bir şekilde açıklamaktadır. Benzer bir şekilde marka nefretinin sonucunda tüketiciler, markadan kaçınmaya ve olumsuz ağızdan ağıza iletişime yönelmektedirler. Araştırma sonuçları, alan yazına dayalı olarak tartışılmış ve uygulamacılara önerilerde bulunulmuştur.
\end{abstract}

Anahtar Kelimler: Marka nefreti, marka kaçınması, ağızdan ağıza iletişim.

JEL Sınıflandırma Kodları: M30, M31

\begin{abstract}
An Empirical Study on Antecedents and Consequences of Brand Hate ${ }^{2}$
Abstract

In the literature on anti-consumption, the relationship of consumers with brands is associated with positive and negative emotions. Brand hate is considered as one of the negative emotions which is defined as a more intense negative emotion towards a particular brand. The aim of this study is to determine antecedents and consequences of brand hate. The data was collected from 215 consumers who have hate for smartphone brands by face-to-face survey method. Consumers' brand hate is limited to high-tech smartphones. Research hypotheses were tested with structural equation model. According to the results, both symbolic incongruity and ideological incompatibility effect brand hate in a positive way. Similarly, brand hate results with brand avoidance and negative word of mouth. The results of this study were discussed on the basis of the literature and suggestions were given to the future research and practitioners.
\end{abstract}

Key words: Brand hate, brand avoidance, negative word of mouth.

JEL Classification Codes: M30, M31

\footnotetext{
1 •Bu çalışmanın genişletilmiş özet hali "Tüketici Marka İlişkilerinin Olumsuz Yönleri Üzerine Bir Araştırma” başlığı ile 23. Pazarlama Kongresinde (27.06.2018) bildiri olarak sunulmuştur.

${ }^{2}$ Extended abstract is presented at the end of the article.
}

Geliş Tarihi (Received): 18.09.2018 - Kabul Tarihi (Accepted): 26.06.2019

Atıfta bulunmak için/Cite this paper:

Balıkçıŏ̆l, B. ve Kıyak, F. M. (2019). Marka nefretinin nedenleri ve sonuçları üzerine görgül bir çalışma. Çankırı Karatekin Üniversitesi İIBF Dergisi. 9 (1), 225-243. 


\section{Giriş}

Tüketiciler sıklıkla ürünleri kendilerine sağladıkları pozitif katkılardan dolayı satın alırlar. Bazı çalışmalar, tüketicilerin markaları kendilerini ifade etmede ve benliklerini oluşturmalarında bir araç işlevi gördüğü için tercih ettiklerini göstermektedir (Solomon, 1983; Belk, 1988; Aaker, 1999). Bunun aksine bazı çalışmalarda ise, tüketicilerin hayatlarına istemedikleri anlamları vermemek için bazı markaları tüketmekten kaçındıkları üzerinde durulmuştur (Holt, 2002; Banister ve Hogg, 2004). Ogilvie (1987) ile Banister ve Hogg (2004), sembolik tüketim bağlamında tüketicinin ne istediğinin bilinmesi kadar ne istemediğinin de ortaya konulmasının önemli olduğunu savunmaktadırlar (Lee, Motion ve Conroy, 2009, s. 169).

Pazarlama alan yazınında tüketicilerin markalarla olan ilişkisi, sevgi gibi pozitif (Khan ve Lee, 2014) ve negatif duygularla (Fetscherin ve Heinrich, 2015) ilişkilendirilmektedir. Tüketicilerin ürün ya da markaya yönelik olumsuz tutumları, tüketim karşıtlığına kadar uzanmaktadır (Penaloza ve Price, 1993; Fournier, 1998; Cherrier, 2009). Tüketim karşıtlığının nedenleri (Zavestoski, 2002) ve türleri (Iyer ve Muncy, 2009) üzerine yapılmış çok sayıda araştırma mevcuttur. Tüketim karşıtlığının bir sonucu olarak ortaya çıkan marka nefreti (Krishnamurthy ve Küçük, 2009; Romani, Grappi ve Dalli, 2012; Zarantonello, Romani, Grappi ve Bagozzi, 2016; Hegner, Fetscherin ve Van Delzen, 2017) ayn zamanda marka kaçınmasına (Hogg, Banister ve Stephenson, 2009; Lee, Conroy ve Motion, 2012) da neden olmaktadır. Kucuk'e göre (2016), marka nefretinin hareket noktası, markaların haksız ve adil olmayan uygulamalarına yönelik tüketici algılarıdır. İlgili alan yazında marka nefretine yönelik çeşitli tanımlar mevcut olmakla beraber (Zarantonello vd., 2016) bu çalışmada Hegner vd.'nin (2017) tanımı esas alınmıştır. Buna göre marka nefreti, bir markadan hoşlanmamaktan ziyade; tüketicilerin geçmiş olumsuz deneyimlerinden, sembolik olarak markanın kimliği ile aralarındaki uyuşmazlıktan ve ahlaki kabullerinden dolayı markayla ideolojik olarak uyuşmazlıktan kaynaklanan yoğun duygusal bir tepkidir. $\mathrm{Bu}$ tepkinin sonucunda tüketiciler, davranışsal olarak ya markaya yaklaşarak ondan intikam almaya çalışırlar veya aktif olarak olumsuz ağızdan ağıza iletişimi de kullanarak markadan kaçınırlar (Hegner vd., 2017).

$\mathrm{Bu}$ çalışma, tüketim karşıtlığı alan yazınında incelenen tüketici marka ilişkilerindeki olumsuz faktörlerin marka nefreti özelinde, etkilerinin belirlenmesi amacıyla Hegner vd.'nin (2017) modeli temelinde nicel bir araştırmaya dayalı olarak gerçekleştirilmiştir. Sembolik uyuşmazlık ve ideolojik uyumsuzluk marka nefretine etki eden faktörler olarak ele alınırken marka kaçınması ve olumsuz ağızdan ağıza iletişim ise marka nefretinin sonuçları olarak incelenmektedir. Alan yazında tüketicilerin markalarla olan olumsuz ilişkilerine yönelik özellikle de marka nefreti çalışmaları sınırlı sayıda olup bu çalışma ile bu alanda Türkiye'deki boşluğu doldurmaya yönelik olmasından dolayı önemlidir. 


\section{Kuramsal Çerçeve}

\subsection{Marka Nefreti}

Psikoloji alan yazınında duyguların tasnif edilmesinde nefret duygusuna nadiren de olsa birincil duygular arasında yer verilmektedir (Arnold, 1960). Buna bağlı olarak nefret, benzer duygularla birlikte gruplandırılır. Örneğin Shaver, Schwartz, Kirson ve O'Conner (1987), duyguları ifade eden 213 kelime arasinda nefret duygusunu öfke duygusunun bir alt kategorisinde konumlandırıldığını tespit etmişlerdir. Her ne kadar nefret ikincil duygu olarak nitelendirilse de bu konuda ortak bir görüşten bahsetmek mümkün değildir. Sternberg (2003), nefretin iğrenme, öfke ve korku ile değersizleştirme olmak üzere üç bileşenini tanımlamaktadır. Çoğu psikolog, nefret duygusunun ortaya çıkışını ahlaki kuralların ihlaline bağlamaktadır. Sternberg'e (2003) göre nefreti oluşturan iğrenme, öfke, korku ve küçümseme gibi duygular, bireysel ya da toplumsal hakların ve özgürlüğün ihlali sonrasında ortaya çıkabilmektedir. Buna göre söz konusu nefret duygusuyla başa çıkmak için bir takım stratejilerin oluşturulması gerekmektedir. Bu stratejilerin bir başka ifadeyle nefret duygusu sonucu ortaya çıkan davranış biçimlerinin çeşitliliğinden bahsedilmesi mümkündür. Çünkü nefret, yalnızca diğerini incitmek ya da yok etmek (Allport, 1958) değil, aynı zamanda ötekini değersizleștirmek ve küçümsemekle de ilgilidir (Sternberg, 2003; Rempel ve Burris, 2005).

Psikoloji ve nöroloji alanında yapılan çalışmalar, insanların olumsuz olayları olumlu olaylardan daha çok hatırladıklarını ortaya çıkarmıştır (Hegner vd., 2017). Buradan hareketle Baumeister, Bratslavsky, Finkenauer ve Vohs (2001), tüketici davranışı alan yazınında tüketicilerin belirli bir ürün veya şirketle ilgili olumlu deneyimlerden ziyade olumsuz deneyimlerini paylaşma eğiliminde olduklarını tespit etmişlerdir. Bu bağlamda daha çok tüketicilerin olumsuz geçmiş deneyimlerinden beslenerek ortaya çıkan marka nefreti, tüketicinin markalara yönelik olumsuz duygularından birisi olarak ele alınmaya başlanmıştır (Zarantonello vd., 2016; Hegner vd., 2017). Marka nefreti, markadan hoşlanmamaktan ziyade bir markaya yönelik daha yoğun olumsuz bir duygu durumu olarak markadan kaçınma ve markaya ilişkin olumsuz ağızdan ağıza iletişime neden olan bir kavram olarak ele alınmıştır. Gregoire, Tripp ve Legoux (2009), marka nefretini intikam ve kaçınma arzusu olarak tanımlamaktadırlar. İntikam arzusu, neden olduğu zararlar için markanın ait olduğu firmanın cezasını çekmesi gerektiği düşüncesini içerirken kaçınma arzusu ise müşterilerin marka ile olan herhangi bir etkileşimden kendilerini çekme düşüncesini kapsamaktadır (Zarantonello vd., 2016, s. 13).

\subsubsection{Marka Nefretinin Nedenleri ve Sonuçları}

Marka nefreti; geçmiş olumsuz deneyimlere, ahlaki kabullerle uyumsuzluğa ve marka ile tüketici benliğinin uyuşmamasına bağlı olarak ortaya çıkabilmektedir 
(Hegner vd., 2017). İstenmeyen benlik ve kimlik tespiti, hangi markaların tüketicilerin benlikleriyle sembolik olarak uyumlu olup olmadığını da ortaya çıkarmaktadır. Tüketiciler, kendileriyle uyumsuz olarak algıladıkları markalardan kaçınarak benlik yapılarının özgünlüğünü korumaya çalışırlar (Grubb ve Grathwohl, 1967; Sirgy, 1982; Englis ve Solomon, 1995; Hogg ve Banister, 2001). Tüketicinin ahlaki kabullerinin işletmenin gerçekleştirdiği eylemlerle örtüşmemesi, markaya karşı olumsuz duyguların oluşumunda etkilidir. İdeolojik uyumsuzluk olarak ifade edilen bu etken, işletmelerin ve dolayisıyla da markaların yasal, sosyal ve ahlaki bağlamlarda yanlış uygulamaları olduğuna dair inançlarıyla ilişkilidir (Hegner vd., 2017).

İdeolojik uyumsuzluk bir diğer marka kaçınması türü olan ahlaki kaçınmanın nedeni olarak ortaya çıkmaktadır. Kozinets ve Handelman (2004) anti tüketim hareketlerinin tüketici ideolojisinde ahlaki ve etik değişiklikler istediğini ileri sürmekte, tüketicilerin tüketim karşıtı görüşleri ve hegemonik markalara yönelik ahlaki muhalefetini incelemektedir. Ahlaki kaçınmanın temeline bakıldığında bireyin ihtiyaçlarını aşan toplumsal bir odak olan baskıcı / egemen güçlere direnmenin belli markalardan kaçınma davranışıyla ahlaki bir görev niteliğine bürünmesidir. Ahlaki kaçınmadan kaynaklanan marka kaçınmasından bahsederken güç dengesizliğinden de söz etmek gerekmektedir. Çokuluslu büyük markalarla tüketici arasındaki gücün dengesizliği ahlaki kaçınmayı motive eder. Bu noktada karşımıza Foucault'nun az ya da çok organize, hiyerarşik, koordine edilmiş ilişki kümeleri arasındaki etkileşim şeklinde tanımladığı iktidar kavramı çıkmaktadır (Foucault, 1980, s. 198). Foucault (1980), iktidarın ve direncin ayrılmaz bir biçimde bağlantılı olduğunu ortaya koymakta; bu nedenle iktidarın olduğu yerde direncin kaçınılmazlığından söz etmektedir. Bu nedenle küresel firmaların mevcudiyeti ahlaki kaçınmanın varlığını da zorunlu kılmaktadır.

Kaynak, Küçükemiroğlu ve Hyder'a (2000) göre tüketim karşıtlı̆̆ı, tüketicilerin markanın menşe ülkesine dair sahip oldukları bilgiyle de doğrudan ilişkilidir. Bir ürünün menşei hakkındaki bilgi, tüketicilerin o ürüne yönelik tutum ve davranışlarını etkilemektedir. Bazen bir ülkenin etik dışı politikası ile markanın menşe ülke bilgisi ilişkilendirilebilir. Ayrıca politik ideoloji ve savaş karşıtı düşünceler de bazı uluslararası ikonlaşmış Amerikan markalarının algılanma biçimini etkilemektedir. Tıpkı bir ülkenin güçlü yönleri bir markayla ayrılmaz bir şekilde bağlantılı olabildiği gibi algılanan hataları da benzer şekilde markayla eşleştirilebilmektedir. Amerikan markalarından kaçınılması ve markaların boykot edilmesi, anti-küreselleşme, savaş karşıtı tutum ve pazar hâkimiyetlerine karşı direnişle bağlantılıdır. McDonald's, bu anlamda politik nedenlerle ilintili ahlaki kaçınma örnekleri arasında yer alabilir. Benzer bir şekilde markanın menşe ülkesiyle bağlantılı olarak finansal yurtseverlik şeklinde isimlendirilecek bir alt başlıktan da bahsedilebilir (Lee, Motion ve Conroy, 2009). Buna göre bazı tüketiciler, aidiyet hissettikleri topluluğun bir parçası olan yerel markalarla bir bağ kurabilmektedir. Söz konusu tüketiciler, kültürel çeşitliliği koruma, küresel 
homojenleşmeye direnme ve alımlarının maddi kârlarının kendi ülkesinde kalmasını sağlama güdüsüyle satın alma davranışlarını gerçekleştirmektedir. $\mathrm{Bu}$ nedenle belirli markalardan ahlaki açıdan kaçınılması çokuluslu markalara yabancılaşmaya neden olabilmektedir (Lee vd.,2009).

Marka nefretinin davranışsal bir sonucu olarak marka kaçınması, tüketicilerin kasitlı olarak bir markadan uzak durmaları veya onu reddetmeleri olarak tanımlanır (Lee vd., 2009, s. 422). Englis ve Solomon (1995) çalışmalarında tüketicinin özellikle negatif bir referans grubuna işaret eden ve bu nedenle özgünlük eksikliği taşıyan veya bireysellik kaybını temsil eden markaları kullanmaktan kaçındıklarını vurgulamaktadırlar. Burada altı çizilmesi gereken, tüketicilerin negatif marka anlamları veya değerleri olarak algıladıkları ürünlerle ilişkili olmak istememeleridir. Kimlik kaçınması söz konusu olduğunda önemli olan markanın fonksiyonel kalitesi değil, sembolik anlamıdır. Örneğin, tekstil sektöründe bulunan bir markayı giyen insan sayısı arttıkça markanın kendine özgü benzersiz bir kimlik yaratma aracı olma özelliği azalır. Bu nedenle öne çıkmayı seven ve özdeş olma düşüncesinden hoşlanmayan tüketici, ana akım olarak yorumladığı çeşitli markalardan kaçınır. Markaların bünyesinde taşıdığı sembolik anlamlar ve bu anlamların bireyin kendilik algısıyla uyumsuzluğu kimlik kaçınmasını motive eder. Tüketici için bazı markalar olumsuz bir referans grubunu çağrıştırabilmekte, sıradanlığı işaret etmekte veya bireyselliğin yitirilmesi anlamına gelebilir. Çünkü hepsi bir bireyin istenmeyen benliğinin yönüdür ve bu nedenle de bu tür markalardan kaçınmalıdır (Lee vd.,2009, s. 173174). Oliva, Oliver ve MacMillan (1992) marka kaçınmasını marka sadakatinin anti tezi olarak kullanmışlardır. Markayla ilgili tatmin marka sadakatini doğururken tatminsizlik de markadan kaçınmaya neden olabilmektedir.

Marka nefreti tüketicide sadece kaçınma davranışını ortaya çıkarmakla kalmaz. Markaya yönelik nefret tüketicide bu nefreti paylaşma isteğini tetikler. Başka bir ifadeyle marka nefreti, olumsuz ağızdan ağıza iletişime de neden olmaktadır. Baumeister vd. (2001), insanların başkalarıyla olumsuz deneyimlerini paylaşma olasılıklarının olumlu bir deneyimi paylaşma olasılıklarından daha yüksek olduğunu savunmaktadır. Olumsuz ağızdan ağıza iletişim ile tüketiciler, çoğunlukla markayla olan olumsuz deneyimleri hakkında başkalarını uyarmak isterler ve bunun yayılımını sağlarlar. Sabah Çelik (2018), marka nefretini taraftarlık kapsamında ele aldığı nitel araştırmada nefretin; kent savunusu, kendi taraftarına övgü ve öteki takıma yönelik karşıtlık olmak üzere üç boyutu olduğunu ortaya çıkmıştır.

\subsection{Araştırma Modeli ve Hipotezler}

Bu çalışmada Hegner vd.'nin (2017) marka nefreti modeli esas alınmıştır. Şekil 1'de gösterildiği gibi sembolik uyuşmazlık ve ideolojik uyumsuzluk marka nefretini pozitif etkileyen öncüller olarak incelenmiştir. Marka nefretinin sonuçları olarak da marka kaçınması ve olumsuz ağızdan ağıza iletişim ele 
alınmıştır. Ayrıca, olumsuz ağızdan ağıza iletişimin marka kaçınmasının bir sonucu olduğu da iddia edilmiştir. Hegner vd.'nin (2017) orjinal araştırma modelinde geçmiş olumsuz deneyimler marka nefretinin bir diğer öncülü olarak incelenmiş olsa da bu çalışmada söz konusu değişken araştırma modelinin dişında tutulmuştur. Zira geçmiş olumsuz deneyimler, sadece markanın mevcut müşterileriyle ilgiliyken sembolik uyuşmazlık ve ideolojik uyumsuzluk değişkenleri markanın müşterisi olmayan ancak markadan nefret edern müşterilerle ilgilidir. Bundan başka, marka nefretinin bir diğer sonucu olan marka misillemesi de bu araştırmanın modelinde kullanılmamıştır. Söz konusu çıktı değişkeni, geçmiş olumsuz deneyimlerin bir sonucu olarak işletme çalışanlarına yönelik veya ürün memnuniyetsizliklerinden dolayı işletmeye yönelik şikayetlerin eşlik ettiği ve bu şekilde markaya yaklaşarak markadan intikam almaya odaklanmaktır. Araştırma hipotezleri aşağıdaki gibi belirlenmiştir.

Marka nefretinin nedenleri ve sonuçları üzerine alan yazında bulunan mevcut çalışmalar değerlendirildiğinde, sembolik uyuşmazlığın marka nefretini doğurduğu görülmektedir. Kressmann, Sirgy, Herrmann, Huber ve Lee (2006) yaptıkları çalışmada, tüketicinin kendilik imajı ile marka imajının örtüştüğü oranda marka sadakatini telaffuz etmenin mümkün olacağı sonucuna ulaşmışlardır. Khan ve Lee (2014), tüketicilerin kendilerine ait benlik tanımlamalarıyla uyumlu imajlara sahip markaları satın almaya eğilimli olduklarını vurgulamaktadırlar. Söz konusu ilişki biçimleri, sembolik uyuşmazlıkla marka nefreti arasındaki ilişkiyi dolaylı olarak doğrulamaktadır. Ayrica Grubb ve Grathwohl (1967) ile Edson, Escalas ve Bettman (2005) sembolik uyuşmazlığın marka nefretini etkilediği sonucuna ulaşan çalışmalar arasındadır. Dolayısıyla çalışmanın ilk hipotezi aşağıdaki şekilde geliştirilmiştir:

$\mathrm{H}_{1}$ : Sembolik uyuşmazlık marka nefretini pozitif ve anlamlı olarak etkilemektedir.

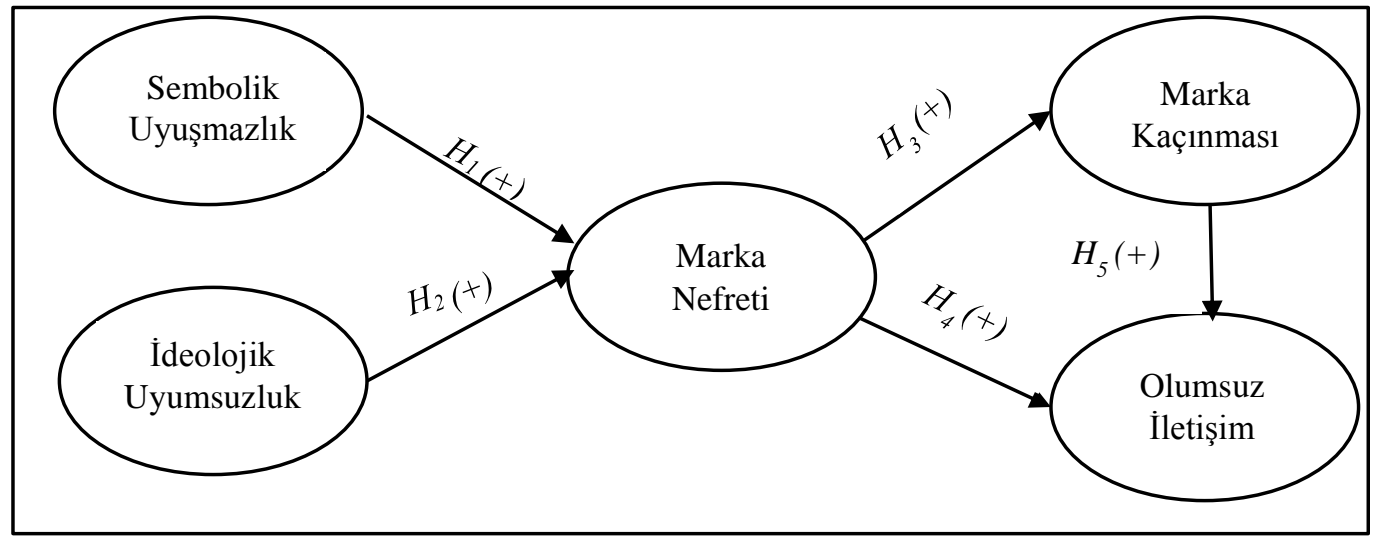

Şekil 1: Araştırma modeli 
Araştırmalar, tüketicilerin etik olmayan alanlarda faaliyet gösteren ya da faaliyet süreçlerinde etik olmayan eylemlerin yer aldığı markaları boykot ettiği gibi insan haklarına saygısız veya çevreye zarar veren markaları onaylamadığını göstermektedir (Friedman, 1985; Micheletti, Follesdal ve Stolle 2004; Sandıkç1 ve Ekici, 2009). Bu nedenle yasal, ahlaki veya sosyal kaygılara bağlı olarak tüketicilerde ideolojik uyumsuzluk algısı gelişmekte ve bu durum marka nefretine neden olmaktadir (Bryson, Atwal ve Hultén 2013; Romani, Grappi, Zarantonello ve Bagozzi 2015; Zarantonello vd., 2016). Dolayısıyla çalışmanın ikinci hipotezi aşağıdaki gibi geliştirilmiştir:

$\mathrm{H}_{2}$ :İdeolojik uyumsuzluk marka nefretini pozitif ve anlamlı olarak etkilemektedir.

Tüketicinin markalara yönelik duygular, davranışların oluşmasına da neden olmaktadır. Olumlu duygular, satın alma niyetinin belirleyicisi olabildiği gibi olumsuz duygular da uzaklaşma ve kaçınma davranışları ile sonuçlanmaktadır (Gregoire vd., 2009; Zarantonello vd., 2016). Söz konusu markaya yönelik duygu \& davranış ilişkisi, marka nefretinin marka kaçınmasını etkilediği sonucunu desteklemektedir ve çalışmanın üçüncü hipotezi şu şekilde geliştirilmiştir:

$\mathrm{H}_{3}$ : Marka nefreti marka kaçınmasını pozitif ve anlamlı olarak etkilemektedir.

Olumsuz ağızdan ağıza iletişim, tüketicinin marka hakkında sözlü veya yazılı olumsuz bildirimde bulunmasıdır (Bonifield ve Cole, 2007). Tüketiciler çoğu zaman markaya dair olumsuz düşüncelerini başkalarına duyurmak ve ilgili marka hakkında başkalarını uyarmak isterler (Singh, 1988). Dolayısıyla marka nefreti, olumsuz iletişime neden olmaktadır ve çalışmanın dördüncü hipotezi aşağıdaki gibi geliştirilmiştir:

$\mathrm{H}_{4}$ :Marka nefreti olumsuz iletişimi pozitif ve anlamlı olarak etkilemektedir.

Gregoire vd. (2009) marka kaçınmasını tüketicilerin kendilerini ilgili markalarla etkileşimlerinden geri çekmeleri olarak ifade etmektedirler. Tüketicilerin kaçındıkları markalar hakkında sahip oldukları olumsuz düşünceleri başkalarına aktarmaları, söz konusu kaçınmanın doğal bir sonucudur. Bu bağlamda marka kaçınması, olumsuz iletişimi doğurmaktadır ve çalışmanın beşinci hipotezi aşağıdaki gibi geliştirilmiştir.

$\mathrm{H}_{5}$ :Marka kaçınması olumsuz iletişimi pozitif ve anlamlı olarak etkilemektedir.

\section{Yöntem}

\subsection{Evren ve Örneklem}

Araştırmanın evreni, amaca uygun olarak marka nefreti olan tüketiciler olarak belirlenmiştir. Ayrıca, Araştırma zaman ve maliyet kısıtlarından dolayı Hatay’ın 
Antakya ilçesinde uygulanmıştır. Evreni oluşturan bireylere ulaşmanın zor olmasından dolayı örneklemin seçiminde kartopu örneklem tekniği kullanılmıştır (Lin, 1976). Bunun için marka nefreti olan birkaç kişiyle görüştükten sonra bu katılımcılar aracılığıyla marka nefreti ölçütüne uyan diğer kişilere de ulaşılmıştır. Marka nefreti, yüksek teknoloji ürünü olan akıllı cep telefonlarıyla sınırlandırılmıştır. Bu amaçla, akıllı telefon markalarına nefreti olan 215 kişiye ulaşılmışıtır.

\subsection{Veri Toplama Yöntemi}

Verilerin toplanmasında yüz yüze görüşme tekniğiyle anket yöntemi kullanılmıştır. Anket formunda marka nefretinin nedenleri olarak araştırılan sembolik uyuşmazlık ve ideolojik uyumsuzluk ile sonuçları olarak incelenen marka kaçınması ve olumsuz ağızdan ağıza iletişimin ölçülmesinde Hegner vd.'nin (2017) çalışması esas alınmıştır. Buna göre marka nefreti altı, sembolik uyuşmazlık beş, ideolojik uyuşmazlık dört, marka kaçınması beş ve olumsuz ağızdan ağıza iletişim de beş madde ile ölçülmüştür. Cevaplayıcıların ifadelere katılım düzeyleri, 5'li Likert tekniğine göre "Kesinlikle Katılmıyorum" 1 ve "Kesinlikle Katılıyorum" 5 puan olacak şekilde belirlenmiştir. Ayrıca anket formunda cevaplayıcılara nefret ettikleri ve hali hazırda kullandıkları akıllı cep telefonu markası ile cinsiyet ve yaş gibi demografik özelliklerine ilişkin sorulara da yer verilmiştir

\subsection{Analiz Yöntemi}

Öncelikle verilerin normal dağılıma uyup uymadıklarına bakılmış, daha sonra da araştırmada kullanılan tüm ölçeklerin güvenilirlik ve geçerlilikleri için Hair, Black, Babin, Anderson ve Tatham'ın (2006, ss. 776-779) önerdikleri işlemler takip edilmiştir. Bunun için Cronbach alfa, birleşik güvenilirlik (CR), ortalama açıklanan varyans (AVE), yakınsak ve ıraksak geçerlilik ölçütleri kullanılmıştır. Faktör yapısını belirlemede açımlayıcı faktör analizi uygulanmış olup ölçeklerin teorik geçerliliğini test etmek için da doğrulayıcı faktör analizi (DFA) kullanılmıştır. Ölçüm modelinin istatistiksel olarak uygunluğu, düzeltilmiş Kikare testi $(\chi 2$ (CMIN) / df), karşılaştırmalı uyum indeksi (CFI) ve karekök ortalama karekök hatası (RMSEA) indeksleri temelinde değerlendirilmiştir. Verilerin analizinde IBM SPSS ve AMOS 24 istatistik programları kullanılmıştır.

\section{Bulgular}

\subsection{Betimleyici İstatistikler}

215 cevaplayıcının \%51.2'si kadın, yaş aralığı 18-30 olup ortalama yaş 23.46'dır. Cevaplayıcıların şu anda kullanmakta oldukları telefon markaları sorulduğunda \%37'si iPhone, \%41'i Samsung, \%5'si LG, \%3'ü Sony ve \%14'ü de diğer markaları kullandıklarını belirtmişlerdir. Cevaplayıcıların \%19'u iPhone, \%18'i 
Samsung, \%16's1 LG, \%11'i HTC, \%8'i Sony, \%5'i Blackberry ve \%23'ü de diğer markalardan nefret ettiklerini belirtmişlerdir. Cevaplayıcılara nefret ettikleri markaları kullanıp kullanmadıkları sorulduğunda ise \%61'i hayır ve \%36'sı da evet cevabını vermiştir.

\subsection{Geçerlilik ve Güvenilirlik Analizleri}

Araştırma verilerinin çarpıklık değeri 1'den küçük ve basıklık değeri 3'den küçük olmak üzere, verilerin normal dağılıma uygun olduğuna karar verilmiştir. Araştırma ölçümünün geçerliliğini test etmek için Kaiser-Meyer-Olkin değeri 0.867 ile örneklem hacminin faktör analizi yapmaya yeterli olduğu ortaya çıkmıştır. Bununla beraber Bartlett's testi istatiksel olarak anlamlı çıkmıştır ( $\mathrm{p}>$ 0.05). Keşfedici faktör analizi, temel bileşenler varimax rotasyon yöntemine göre yapılmış ve alan yazına uygun beş faktörlü yapıya ulaşılmıştır. Oluşturulan faktör yapısı, varyansın \%68.3'ünü açıklamaktadır. Ölçüm modelinin geçerliliğine ilişkin DFA sonuçları Tablo 1'de verilmiştir.

DFA sonucuna göre faktör yükleri (Tablo 1) 0.50'nin altında kalan beş madde, ölçüm modelinden çıkarılarak analiz tekrar edilmiş ve tüm faktör yükleri, 0.001 düzeyinde istatistiksel olarak anlamlı çıkmıştır. Analiz sonuçlarına göre ölçüm modelinin uyum iyiliği değerleri kabul edilebilir değerleri sağlamıştır (Hair vd., 2010). Buna göre: Ki-Kare $=224.291 ; \mathrm{sd}=158 ; \mathrm{p}<0.001$; $\mathrm{TLI}=0.945 ; \mathrm{CFI}=$ 0.958; RMSEA = 0.052 olarak bulunmuştur.

Cronbach Alpha ve birleşik güvenilirlik değerleri (CR), değişkenlerin güvenilir olduklarını göstermektedir (Tablo 2). Ölçüm modelinde kullanılan değişkenlere ilişkin tüm CR değerleri, ortalama açıklanan varyans (AVE) değerlerinden büyüktür. AVE değerleri de 0.50 'den büyük olduğu için yakınsak geçerlilik sağlanmıştır. Değişkenlerin maksimum paylaşılan varyansının karesi (0.218), AVE değerinden küçük ve AVE' nin karekökü faktörler arası korelasyondan büyük olduğu için ıraksak geçerlilik de sağlanmıştır.

Araştırma hipotezleri, yapısal eşitlik modeli ile test edilmiştir. Yapısal model, istatiksel olarak kabul edilebilir düzeydedir (Ki-Kare $=262.203 ; s d=163 ; p$ $\mathrm{p}<0.001 ; \mathrm{TLI}=0.923 ; \mathrm{CFI}=0.934 ; \mathrm{RMSEA}=0.064)$. Analiz sonuçlarına göre sembolik uyuşmazlık $(\beta=0.27 ; p \leq 0,001)$ ve ideolojik uyumsuzluk $(\beta=0.39 ; p \leq$ $0.001)$ marka nefretini anlamlı bir şekilde etkilemektedir. Bununla beraber marka nefreti, marka kaçınması $(\beta=0,28 ; p \leq 0.001)$ ve olumsuz ağızdan ağıza iletişimi $(\beta=0,26 ; p \leq 0.001)$ anlamlı olarak etkilemektedir. Son olarak da marka kaçınması, negatif ağızdan ağıza iletişime $(\beta=0,49 ; p \leq 0.001)$ neden olmaktadır. Buna göre araştırmanın tüm hipotezleri desteklenmiştir. Araştırmanın bağımsız değişkenleri, marka nefretindeki değişimin \%23'ünü açıklamaktadır. Marka nefreti, negatif ağızdan ağıza iletişimdeki değişimin \%37'sini marka kaçınmasını da çok düşük (\%8) düzeyde açıklamaktadır. 
Tablo 1: Doğrulayıcı faktör analizi sonuçları

\begin{tabular}{|c|c|c|}
\hline \multirow{2}{*}{$\begin{array}{l}\text { Değişkenler } \\
\text { Sembolik Uyuşmazlık (SU) }\end{array}$} & \multicolumn{2}{|c|}{ Standardize Faktör Yükleri } \\
\hline & SU3 & 0.667 \\
\hline & SU4 & 0.793 \\
\hline & SU5 & 0.776 \\
\hline \multirow[t]{3}{*}{ İdeolojik Uyumsuzluk (İU) } & İU2 & 0.628 \\
\hline & İU3 & 0.763 \\
\hline & İU4 & 0.766 \\
\hline \multirow[t]{4}{*}{ Marka Nefreti (MN) } & MN3 & 0.684 \\
\hline & MN4 & 0.720 \\
\hline & MN5 & 0.795 \\
\hline & MN6 & 0.909 \\
\hline \multirow[t]{5}{*}{ Marka Kaçınması (MK) } & MK1 & 0.704 \\
\hline & MK2 & 0.778 \\
\hline & MK3 & 0.800 \\
\hline & MK4 & 0.827 \\
\hline & MK5 & 0.844 \\
\hline \multirow[t]{5}{*}{ Olumsuz Ağızdan Ağıza İletişim (OAİ) } & OAİ1 & 0.702 \\
\hline & OAİ2 & 0.790 \\
\hline & OAİ3 & 0.841 \\
\hline & OAİ & 0.685 \\
\hline & OAİ5 & 0.808 \\
\hline
\end{tabular}


Tablo 2: Geçerlilik ve güvenilirlik analizi sonuçları

\begin{tabular}{|l|l|l|l|l|l|l|l|}
\hline & CR & AVE & $\boldsymbol{\alpha}$ & $\mathbf{1}$ & $\mathbf{2}$ & $\mathbf{3}$ & $\mathbf{4}$ \\
\hline 1.SU & 0.790 & 0.558 & 0.806 & 1 & & & \\
\hline 2.IU & 0.764 & 0.521 & 0.775 & $0.270^{* *}$ & 1 & & \\
\hline $3 . \mathrm{MN}$ & 0.861 & 0.611 & 0.868 & $0.304^{* *}$ & $0.350^{* *}$ & 1 & \\
\hline 4.MK & 0.893 & 0.627 & 0.902 & $0.390^{* *}$ & $0.205^{* *}$ & $0.312^{* *}$ & 1 \\
\hline 5.OAİ & 0.876 & 0.589 & 0.874 & $0.288^{* *}$ & $0.239^{* *}$ & $0.384^{* *}$ & $0.467 * *$ \\
\hline
\end{tabular}

\section{Sonuç, Öneriler ve Kısıtlar}

$\mathrm{Bu}$ çalışma, sembolik uyuşmazlığın ve ideolojik uyumsuzluğun marka nefreti üzerindeki etkisi ile marka nefretinin birer sonucu olarak marka kaçınması ve olumsuz ağızdan ağıza iletişimi ilişkilerinin yapısal bir modelle belirlemeye yönelik olarak gerçekleştirilmiştir. Araştırma modeli, Hegner vd.'nin (2017) çalışmasını destekleyecek şekilde istatistiksel olarak iyi düzeyde parametre tahminleri ile teoriyle tutarlı sonuçlar üretmiştir. $\mathrm{Bu}$ modelin kayda değer özellikleri, istatistiksel olarak anlamlı standartlaştırılmış regresyon katsayıları ile gösterildiği üzere, mevcut veriyle tüketicinin markalarla olan olumsuz ilişkisini marka nefreti özelinde içermektedir.

Araştırmanın sonuçlarına göre hem sembolik uyuşmazlık hem de ideolojik uyumsuzluk, marka nefretini anlamlı bir şekilde açıklamaktadır. Benzer bir şekilde marka nefreti de markadan kaçınmayı ve olumsuz ağızdan ağıza iletişime neden olmaktadır. Dolayısıyla da bu sonuçlar, Hegner vd.'nin (2017) Alman tüketiciler üzerinde yaptıkları çalışmayı destekler nitelikte ortaya çıkmıştır. Underhill (2012), sevgi ve nefretin sosyal ve kültürel bağlama göre şekillendiğini belirtse de, bireyci bir kültür olan Almanya'da ve toplulukçu bir kültüre sahip Türkiye'de marka nefretiyle ilgili benzer sonuçların çıkmış olması bu tür olguların kültürden bağımsız olarak da gelişebileceğine dair bir sonuç olarak değerlendirilebilir.

Sembolik olarak tüketicilerin benlik-kavramını bir markanın tipik bir kullanıcısının kişiliği ile ne düzeyde eşleştirdiklerini ifade eden benlik-uyumu (Sirgy, 1982) değer ifade eden markaların başarısını büyük ölçüde belirlemektedir. Zira marka kişilikleri ile hedeflenen tüketicilerin kimlikleri arasındaki uyum, tüketicilerin markaya yönelik tutumlarını ve satın alma niyetlerini olumlu etkiler. Bundan dolayı işletmelerin, markalarına yönelik sembolik uyumsuzluk nedenlerini araştırarak marka nefretinin oluşmaması için gerekli bazı önlemleri alması gerekir. Hegner vd'nin (2017) vurguladığı gibi sembolik uyumsuzluk farklı nedenlerden kaynaklanabilmektedir. Markanın 
negatif bir referans grubunu temsil etmesi veya negatif sembolik bir anlam taşıması seçenekler arasındadır. $\mathrm{Bu}$ nedenle, hedef tüketicilerin kendileriyle özdeşleştirdikleri kullanıcı tipine yönelik iletişim çabalarının yapılması uygun olacaktır.

İdeolojik uyumsuzluğun marka nefretini sembolik uyuşmazlığa göre yüksek düzeyde etkiliyor olması, şirketlerin sosyal ve ahlaki bağlamda sorumluklarını daha dikkatli bir şekilde yerine getirmeleri gerektiğinin bir göstergesi olarak göz önünde bulundurulmalıdır. Zira markaya yönelik olumsuz duygular, işletmelerin yasal, sosyal veya ahlaki olarak yanlış uygulamalarla ilişkilendirilmektedir. İşletmelerin yanıltıcı reklamları veya markanın değerleriyle uyuşmayan vaatleri buna örnek verilebilir. İdeolojik uyumsuzluğun bağlamı, sembolik uyumsuzluktaki gibi tüketicinin benlik kurgusundan öte toplumsal veya ahlaki bir bağlamla ilişkilidir (Lee vd., 2009). Tüketiciler, bireysel düzeyde kendilerine olumsuz gelen bazı uygulamaları işletmelerin satış teşviklerinin (ekstra \%20 indirim olanağ1 gibi) etkisinde kalarak unutabilirler. Ancak, toplumu ilgilendiren uygulamalarda negatif sonuçlara aynı şekilde telafi etmeyebilirler.

Marka nefretinin sonucunda marka kaçınması ve buna bağlı olarak da olumsuz ağızdan ağıza iletişimin oluşuyor olması, bir diğer önemli sonuçtur. Kucuk'un (2008) belirttiği gibi yönetsel açıdan bakıldığında bu tür sonuçlar, işletmeler için krizlere neden olabilir. Zira günümüzde sosyal medya aracılığıyla tüketiciler, olumsuz duygularını kolaylıkla her yere yayabilme gücüne sahip olmuşlardır. Özellikle de marka nefretine yönelik internet sayfalarının oluşumu, doğrudan veya dolaylı olarak marka kimliği ve imajına zarar verebilme özelliği ile tüketicilerin satın alma kararlarını da etkileyebilmektedir (Kucuk, 2008).

$\mathrm{Bu}$ nedenle şirket yönetiminin stratejik markalama kararları ile proaktif önlemler alarak oluşabilecek krizleri önleme becerilerini geliştirmeleri gerekmektedir. Bunun için şirketler öncelikle, müşterilerle ilk temas noktasında etkileşimde bulunan çalışanları ile müşteri hizmetleri bölümü çalışanlarını sürekli olarak izlemesi gerekir. Aynı zamanda internet ortamında ve özellikle de sosyal medyadaki ürüne veya şirkete dair şikâyetler, hızlı bir şekilde çözüme kavuşturulmalı ve memnuniyet ölçümleri yapılmalıdır. İşletmelerin, tüketicilerle etkileşim içerisinde bulundukları her türlü platformda müşterilerden gelen geribildirimleri sürekli izlemesi ve bu bildirimi başarılı bir şekilde yönetmesi; tüketici marka ilişkilerini etkin ve verimli bir şekilde yönetilmesine ve varsa uygun önlemlerin alınmasında etkili olacaktır. Ayrıca sosyal sorumluluk projeleri ile çevre dostu ve/veya sosyal nedenlere dayalı işletme imajının pekiştirilmesi yanında ücretlendirmede adil davranılmasıyla ideolojik uyumsuzluğa neden olan marka nefretinin önüne geçilebilecektir.

$\mathrm{Bu}$ çalışmanın sınırlıkları, akıllı cep telefonu markalarına karşı nefreti olan tüketicilerin dahil olduğu örneklem büyüklüğü ve coğrafi bağlamdır. Bu nedenle, gelecekteki araştırmalar, giyim ve gıda gibi farklı sektörlerdeki markaları da 
kapsayacak şekilde geniş bir örneklem üzerinde yapılabilir. Bundan başka, marka nefretini tetikleyen bir diğer faktör olan markayla yaşanan geçmiş olumsuz deneyimlerin etkisi ile beraber marka nefretinin sonuçlarından birisi olan markadan öç alma da modele eklenerek araştırma modeli genişletilebilir. Bunun dışında tedarik ve dağıtım kanallarında yer alan kurumsal kişiliklerle son tüketicinin olumsuz ağızdan ağıza iletişim davranışı arasında ayrım yapılarak nedenlerinin benzerlik ve farklılıkları değerlendirilebilir. Son olarak marka nefretinin ticari iş ilişkileri ve birlikte markalama durumlarına etkisi de gelecekte yapılacak çalışmaların konuları arasında yer alabilir.

Sonuç olarak, araştırmanın modeli verilere iyi uyum gösterip teorik olarak tutarlı bulgular sağlasa da, veriye iyi uyum gösterebilecek başka modellerin de olabileceğini unutmamak gerekir. Verilere bu modelden daha iyi uyan eşdeğer olmayan alternatif modeller de olabilir. Araştırmacılar, olası alternatif modelleri test etmelidirler.

\section{Kaynakça}

Aaker, JL. (1999)." The malleable self: the role of self-expression in persuasion." Journal of Marketing Research. 36(1):45-57.

Allport, G.W. (1958). The Nature of Prejudice. New York: Doubleday Anchor Book.

Arnold, M.B. (1960). Emotion and Personality. New York: Columbia University Press.

Banister, EN. ve Hogg, MK. (2004). "Negative symbolic consumption and consumers' drive for self-esteem." European Journal of Marketing. 38(7):850-68.

Baumeister, R. F., Bratslavsky, E., Finkenauer, C., ve Vohs, K. D. (2001). "Bad Is Stronger Than Good." Review of General Psychology. 5:323-370.

Belk, R. (1988). "Possessions and the extended self." Journal of Consumer Research.15: 139-68.

Bonifield, C. ve Cole, C. (2007). "Affective responses to service failure: anger, regret, and retaliatory versus conciliatory responses." Marketing Letters.18: 85-99.

Braunsberger, K. ve Buckler, R. B. (2011). "What motivates consumers to participate in boycotts: Lessons from the ongoing Canadian seafood boycott." Journal of Business Research. 64: 96-102. 
Bryson, D., Atwal, G. ve Hultén, P. (2013). "Towards the conceptualisation of the antecedents of extreme negative affect towards luxury brands" Qualitative Market Research: An International Journal. 16: 393-405.

Cherrier, H. (2009). "Anti-consumption discourses and consumer-resistant identities." Journal of Business Research. 62:181-190.

Edson Escalas, J. ve Bettman, J. (2005). "Self-construal, reference groups, and brand meaning" Journal of Consumer Research. 32:378-389.

Englis, B. ve Solomon, M. (1995). "To be and not to be: Lifestyle imagery reference groups, and the clustering of America" Journal of Advertising. 24(1):13-28.

Fetscherin, M. ve Heinrich, D. (2015). "Consumer brand relationships research: A bibliometric citation meta-analysis." Journal of Business Research.68: 380-390.

Foucault, M. (1980). Power/Knowledge: Selected interviews and other writings 1972-1977. New York: Pantheon.

Fournier, S. (1998). "Consumers and Their Brands: Developing Relationship Theory in Consumer Research". Journal of Consumer Research.24: 343373.

Friedman, M. (1985)." Consumer boycotts in the United States, 1970-1980: Contemporary events in historical perspective." Journal of Consumer Affairs.19(1):96-117.

Gregoire, Y., Tripp, T. ve Legoux, R. (2009). "When Customer Love Turns into Lasting Hate: The Effects of Relationship Strength and Time on Customer Revenge and Avoidance. " Journal of Marketing. 73 (6):18-32.

Grubb, EL. ve Grathwohl, HL. (1967). "Consumer self-concept, symbolism and market behavior: a theoretical approach." Journal of Marketing. 31: 22-7.

Hegner, S., Fetscherin, M. ve Delzen, MV. (2017) "Determinants and outcomes of brand hate."Journal of Product \& Brand Management.26(1):13-25.

Hogg, MK. ve Banister, EN. (2001). " Dislikes, distastes and the undesired self: conceptualising and exploring the role of the undesired end state in consumer experience." Journal of Marketing Management. 17: 73-104.

Hogg, M.K., Banister, E.N. ve Stephenson, C.A. (2009). "Mapping Symbolic Anti-) Consumption." Journal of Business Research.62: 148-159. 
Holt, DB. (2002). "Why do brands cause trouble? A dialectical theory of consumer culture and branding." Journal of Consumer Research. 29:7090 .

Iyer, R. ve Muncy, JA. (2009). "A Purpose and object of anti- consumption." Journal of Business Research. 62: 160-168.

Kaynak, E., Küçükemiroğlu, O., ve Hyder, AS. (2000). “Consumer's country-oforigin perceptions of imported products in a homogenous less-developed country." European Journal of Marketing. 34(9/10):1221-41.

Khan, MA., ve Lee. MS. (2014). "Prepurchase Determinants of Brand Avoidance: The Moderating Role of Country-of-Origin Familiarity." Journal of Global Marketing.27: 329-343.

Kozinets, RV., ve Handelman, JM. (2004). "Adversaries of consumption: consumer movements, activism, and ideology." Journal Consumer Research.31(3):691-704.

Kressmann, F., Sirgy, M.J., Herrmann, A., Huber, F., Huber, S. ve Lee, D.J. (2006). "Direct and indirect effects of self-image congruence on brand loyalty." Journal of Business Research. 59 (9):955-964.

Krishnamurthy, S. ve Kucuk, S. (2009). "Anti-Branding on the Internet.” Journal of Business Research.62 (11):1119-1126.

Kucuk, S.U. (2008), "Negative double jeopardy: the role of anti-brand sites on the internet", Journal of Brand Management, 15: 209-222.

Lee, MS., Motion J., ve Conroy, D. (2009)."Anti-consumption and brand avoidance," Journal of Business Research. 62 (2): 169 - 180.

Lee, MS., Conroy D, ve Motion, J. (2012)." Brand avoidance, genetic modification, and brandlessness" Australasian Marketing Journal. 20: 297 $-302$.

Lin, S. H. (1976). "Rain-Rate Distribitions and Extreme-Value Statistics." Bell System Technical Journal. 55: 111-1124.

Micheletti, M., Follesdal, A. ve Stolle, D. (2004). Politics, Products, and Markets: Exploring Political Consumerism Past and Present. New Brunswick: Transaction Publishers.

Ogilvie, DM. (1987)." The undesired self: a neglected variable in personality research." Journal of Personality and Social Psychology.52(2):379-85. 
Oliva, TA., Oliver,RL. ve MacMillan, IC. (1992). "A catastrophe model for developing service satisfaction strategies." Journal of Marketing. 56(3):83-95.

Opotow, S., ve McClelland, S.I. (2007). "The intensification of hating: a theory." Social Justice Research. 20(1):68-97.

Penaloza, L. ve Price, LL. (1993). " Consumer resistance: a conceptual overview." Advences in Consumer Research. 20: 123-8.

Rempel, J.K. ve Burris, C.T. (2005). "Let me count the ways: an integrative theory of love and hate." Personal Relationships. 12 (2):297-313.

Romani, S., Grappi, S., ve Dalli, D. (2012). "Emotions that drive consumers away from brands: Measuring negative emotions toward brands and their behavioral effects." International Journal of Research in Marketing.29(1):55-67.

Romani, S., Grappi, S., Zarantonello, L. ve Bagozzi, R. (2015). "The revenge of the consumer! How brand moral violations lead to consumer anti-brand activism." Journal of Brand Management. 22(8):658-672.

Sabah Çelik, Ş. (2018). “Ankara'nın Bebesi Güçlü Olur: Taraftarlık ve Marka Nefreti Kapsamında Ankaragüçlü Olmak". 23. Pazarlama Kongresi Bildiri Kitabl, 1-23. erişim Adresi: http://pazarlama.org.tr/uploads/files/upk23.pdf

Sandikçı, Ö. ve Ekici, A. (2009). "Politically motivated brand rejection". Journal of Business Research. 62: 208-217.

Shaver, P., Schwartz, J., Kirson, D. ve O’Conner, C. (1987).“Emotion knowledge: further exploration of a prototype approach." Journal of Personality and Social Psychology. 52(6):1061-1086.

Singh, J. (1988). "Consumer complaint intentions and behavior: definitional and taxonomical issues" Journal of Marketing. 52: 93-107.

Sirgy, JM. (1982). "Self-concept in consumer behavior: a critical review." Journal Consumer Research. 9: 287-300.

Solomon, MR. (1983). "The role of products as social stimuli: a symbolic interactionism perspective." Journal Consumer Research.10 (3):319-29.

Sternberg, R.J. (2003). "A duplex theory of hate: development and application to terrorism, massacres, and genocide." Review of General Psychology. (7) 3: 299-328. 
Underhill, JW. (2012). Ethnolinguistics and cultural concepts: truth, love, hate and war. Cambridge: Cambridge University Press.

Zarantonello, L, Romani, S., Grappi, S. ve Bagozzi, R. (2016) "Brand hate." Journal of Product \& Brand Management. 25 (1):11-25.

Zavestoski, S. (2002)." The social-psychological bases of anti-consumption attitudes."Psychology and Marketing.19: 149-65. 


\section{An Empirical Study on Antecedents and Consequences of Brand Hate}

\section{Extended Abstract}

\section{Introduction}

In marketing literature, consumer and brand relationships are associated with positive (Khan and Lee, 2014) and negative emotions (Fetscherin and Heinrich, 2015). The negative attitudes of consumers towards the product or brand extend over to anti-consumption (Penaloza and Price, 1993; Fournier, 1998; Cherrier, 2009). There are numerous studies on the causes of anticonsumption (Zavestoski, 2002) and its forms (Iyer and Muncy, 2009). The brand hate that emerged as a result of anti-consumption (Krishnamurthy and Kucuk, 2009; Romani, Grappi and Dalli, 2012; Zarantonello, Romani, Grappi and Bagozzi, 2016; Hegner, Fetscherin and Van Delzen, 2017) also causes brand avoidance (Hogg, Banister and Stephenson, 2009; Lee, Conroy and Motion, 2012). According to Kucuk (2016), the starting point of brand hate is the consumer perceptions that about unfair and wrong practices of brands. There are several definitions about brand hate in the related literature (Zarantonello et al., 2016). In this study Hegner et al.'s (2017) brand hate definition is used. Accordingly brand hate, rather than dislike a brand, is an intense emotional reaction arising from due to the past negative experiences of consumers, the discrepancy of symbolic identity, and ideological incompatibility of the brand (Hegner et al., 2017).

Brand hate may occur due to past negative experiences, incongruity with moral acceptances and incompatibility between brand and consumer selfConsumers deliberately do not choose brands which is incompatible with their self-concepts (Grubb and Grathwohl, 1967; Sirgy, 1982; Englis and Solomon, 1995; Hogg and Banister, 2001). The fact that the consumer's moral acceptance does not coincide with the actions carried out by the business is effective in the formation of negative feelings towards the brand. This factor, which is expressed as ideological incompatibility, is associated with beliefs that brands have wrong practices in legal, social, and moral contexts (Hegner et al., 2017). As a consequence of brand hate, consumers either try to take revenge by approaching the brand or avoid brand by actively using negative mouth-to-mouth communication (Hegner et al., 2017).

The aim of this study is to determine antecedents and consequences of brand hate in Turkey based on Hegner et al.'s (2017) model. According to this, while symbolic incongruity and ideological incompatibility are considered as the antecedents of brand hate, brand avoidance and negative mouth-to-mouth communication are examined as the consequences of brand hate.

\section{Method}

In accordance with the purpose of this study, snowball sampling technique (Lin, 1976) is used in gathering the data. For this purpose, 215 consumers who hate a specific smartphone brand have been reached. Half of the participants, with 50 percent, was women and the average age is 23.46 .

Data were collected through face-to-face interview method. The scales which is used in Hegner et al.'s (2017) research were modified to reflect smartphone brands used in this study. All items were measured on a five-point Likert type scale whose answers ranged from 'Strongly Disagree' to 'Strongly Agree'.

The reliability and validity of the scales tested by following Hair et al.'s (2006) procedures. The Cronbach's alpha coefficients of all scales that used in this study were over 0.70 and the average 
explained variance values were also greater than 0.50 . Confirmatory factor analysis was used to test the theoretical validity of the scales.

\section{Results}

All hypotheses were tested through structural equation modeling. The estimated structural model showed good fits as Chi-Square $=262.203 ; d f=163 ; \mathrm{p}=0.000 ;$ TLI $=0.923 ;$ CFI $=0.934$; RMSEA $=0.064$. According to the results of the analysis, symbolic incongruity $(\beta=0.27 ; p<$ $0.001)$ and ideological incompatibility $(\beta=0.39 ; p<0.001)$ were positively associated with brand hate. Also, brand hate was positively associated with brand avoidance $(\beta=0.28 ; p<0.01)$ and negative mouth-to-mouth communication $(\beta=0.26 ; \mathrm{p}<0.01)$. Finally, brand avoidance results has a positive effects on negative mouth-to-mouth communication $(\beta=0.49 ; p<0.001)$. Accordingly, all hypotheses of this study were supported.

\section{Conclusion}

This study extend current consumer and brand relationship literature by investigating an empirical study on brand hate in Turkey. The results of this study showed that brand hate is triggered by symbolic incongruity and ideological incompatibility and leads brand avoidance and negative mouth-to-mouth communication. Furthermore, ideological incompatibility effects brand hate at a higher level than symbolic incongruity. Another important results of this study is that the effects of brand avoidance on negative mouth-to-mouth communication. Therefore, these results have provided support the work of Hegner et al. (2017) which is conducted on German consumers.

Symbolically, the self-congruence (Sirgy, 1982), which expresses the extent to which consumers match the self-concept with the personality of a typical user of a brand (Sirgy, 1982), largely determines the success of the brands expressing value. Because of the congruence between the identities of the consumers and the targeted consumers positively affects the attitudes of the consumers towards the brand and the purchasing intentions. Therefore, companies should take the necessary precautions to prevent brand hate by investigating the causes of symbolic incongruity for their brands. The fact that the ideological mismatch affects the brand hate at a high level compared to the symbolic conflict should be considered as an indication that companies should fulfill their responsibilities more socially and morally.

As Kucuk (2008) indicates, from a managerial point of view, such results can cause crises for firms. Today, through social media, consumers have the power to spread their negative emotions easily everywhere. In particular, the formation of web pages for brand hate can affect the purchasing decisions of consumers directly or indirectly with the ability to damage their brand identity and image.

This study has some limitations. First, the model focuses on smartphone brands' hate with crosssectional data. Second, the sample size and geographic context, may have had an impact on findings. For this reason, future research can be carried out on larger sample with different brands in different sectors such as clothing and fast-food. 